\title{
Maternal Serum Levels of Interferon-gamma, Tumor Necrotic Factor-alpha and Progesterone of Infertile Women on In vitro Fertilization before and after Treatment
}

\author{
N. Osakue ${ }^{1}$, C. C. Onyenekwe ${ }^{1}$, F. A. Ehiaghe ${ }^{1,2^{*}}$, J. E. Ahaneku ${ }^{1}$, \\ J. I. Ikechebelu ${ }^{3}$, G. O. Igberase ${ }^{4}$ and L. O. Alekwe ${ }^{5}$ \\ ${ }^{1}$ Department of Medical Laboratory Science, Nnamdi Azikiwe University, Awka, Nigeria. \\ ${ }^{2}$ Molecular Biology Unit, lykenson Medical and Diagnostic Laboratories, Road 2 Mofor Estate Unizik \\ Temporary Site, Awka, Nigeria. \\ ${ }^{3}$ Department of Obstetrics and Gynaecology, Nnamdi Azikiwe University Teaching Hospital, Nnewi, \\ Anambra State, Nigeria. \\ ${ }^{4}$ Shepherd Fertility Hospital, Warri, Delta State, Nigeria. \\ ${ }^{5}$ Lily Hospitals LTD, Warri, Delta State, Nigeria.
}

Authors' contributions

This work was carried out in collaboration among all authors. Authors CCO and NO designed the study. Author CCO sourced for funding. Authors GOI, JII and LOA provided the research participants and administered questionnaires. Authors CCO, NO and FAE wrote the protocol. Authors NO, FAE and JEA contributed in literature search. Authors CCO, JEA and JII gave professional and protocol advise. Authors NO and FAE did the experiments. Authors FAE and NO did statistical analysis. Authors FAE, NO and CCO drafted the manuscript. Authors CCO and JEA supervised the study. Authors NO and FAE Wrote the final manuscript. Authors CCO, JEA and FAE proofread the manuscript. All authors read and approved the final manuscript.

Article Information

DOI: $10.9734 / A R R B / 2020 / v 35 i 430210$ Editor(s):

(1) Dr. David E. Martin, DFH Pharma Inc., USA

Reviewers:

(1) Rana Choudhary, Wockhardt Hospital, India.

(2) Wilson Obidah, Modibbo Adama University of Technology, Yola, Nigeria

(3) Eze Ejike Daniel, Kabale University, Uganda. Complete Peer review History: http://www.sdiarticle4.com/review-history/56246 


\section{ABSTRACT}

Background: In vitro fertilization (IVF) is an assisted reproductive technology (ART) that is widely used globally in the treatment of infertility. Infertility can occur due to male factors, female factors or both.

Aim: This is the first Nigerian study that sets out to observe the levels and relationship between circulating pro-inflammatory cytokines (IFN- $\gamma$, TNF- $\alpha$ ) and progesterone (PG) in Nigerian women undergoing in vitro fertilization pre and post treatment and their possible effect on pregnancy outcome.

Materials and Methods: This observational study randomly selected sixty-two (62) infertile females below 45 year of age who enrolled in the IVF treatment at Lily Hospitals, Warri and Shepherd Specialist Hospital, Warri, Southern Nigeria. Only data of the thirteen (13) infertile females who became pregnant after the IVF treatment where followed up and presented in this study. Five (5) ml of whole blood were collected into plain tubes on day 3 of the menstrual cycle of all the participants from the ante-cubital vein before and after IVF procedure using standard laboratory collection technique. Ovarian stimulation was done using the long gonadotropin-releasing hormone agonist protocol. Oocyte retrieval transfer was done using ultrasound-guided fine-needle aspiration and embryo transfer was done using ultrasound-guided embryo transfer. IFN- $\gamma$, TNF- $\alpha$ and PG were estimated using enzyme-linked immunosorbent assay method.

Results and Conclusion: Significant increase in the levels of TNF- $\alpha$ and PG at the second trimester and third trimester of pregnancy when compared with the first trimester of pregnancy $(p=$ $0.000)$. While the level of IFN- $\gamma$ was significantly increased in the second trimester of pregnancy when compared with the first trimester of pregnancy $(p=0.000)$. It is evident from the study that both pro-inflammatory cytokines (IFN-y and TNF- $\alpha$ ) act in synergy to maintain the level of progesterone which act as an anti-inflammatory agent to regulate the activities of the proinflammatory cytokines for successful oocytes implantation and maturation.

Keywords: Cytokines; immune activation; oocyte implantation; ovarian stimulation.

\section{INTRODUCTION}

In vitro fertilization (IVF) is an assisted reproductive technology (ART) that is widely used globally in the treatment of infertility. Infertility can occur due to male factor (such as poor sperm quality or total absence of sperm), female factors (including tubal blockage, hormonal imbalance, fibroids, ovarian factors, structural damage to the uterus) or both [1]. Hormones and other regulatory substances such as cytokines involved in these mechanisms are either locally secreted within the ovary or are produced at other sites from where they are secreted to act on the ovaries. Furthermore, the concentration of these regulatory substance at specific times of antral follicle development is likely to be related to the success or failure of various developmental processes during IVF [2].

It had been reported that pro-inflammatory cytokines such as interferon gamma and tumor necrotic factor- alpha are involved in implantation success or failure in assisted reproduction [3]. The Concentrations of IL- 1 and TNF- $\alpha$ in human follicular fluid, in relation to IVF results, were analyzed previously by two independent studies $[4,5]$. In which a positive correlation between IL-1 and TNF- $\alpha$ concentrations, but correlation between the concentration of either cytokine and oocyte fertilization was not considered as part of that study. It also had been reported that tumor necrotic factor (TNF- $\alpha$ ) is a potent multifunctional cytokine involved in autocrine and paracrine process such as gamete, follicle and luteal development, steroidogenesis, placental differentiation, development of the embryo and parturition and plays a regulatory role in cell proliferation $[6,7]$.

Studies had shown that successful implantation indicated by increased serum progesterone stimulates the synthesis of progesterone induced binding factor (PIBF) which is secreted by lymphocytes, promotes differentiation of CD4+ T cells into helper T cells 2 (Th2) that secrete high concentrations of anti-inflammatory cytokines, which prevent possible immunological complication associated with pregnancy [8].

Normal pregnancy is considered to be a state of controlled mild maternal systemic inflammation which results in increased circulating levels of 
cytokines such as IFN-Y and TNF-a. [9] Raghupathy [10] reported that pro-inflammatory cytokines IFN- $\gamma$ and TNF- $\alpha$ can damage the placenta and developing fetus either directly or by activating cytotoxic cells, including natural killer cells or T cells. Jenkins et al. [11] and Reid et al. [12] also reported from their studies that circulating IFN- $\gamma$ and TNF- $\alpha$ levels are higher in subjects with subsequent miscarriages compared with those with successful pregnancies. Ehiaghe et al. [13] reported that the elevation of human chorionic gonadotropin hormone, fibrinogen concentration and erythrocyte sedimentation rate during pregnancy are immune adaptive mechanism of blastocyst to get implanted onto the walls of the endometrium where it can obtain nourishment and prevent any possible rejection by the maternal immune system.

A number of non-Nigerian studies have attempted to find a relationship between the concentration of steroids [14-17], pituitary hormones [18] and cytokines $[5,17]$ in the follicular fluid of infertile women on In vitro fertilization. This is the first Nigerian study that sets out to observe the levels and relationship between circulating pro-inflammatory cytokines (IFN-y, TNF- $\alpha$ ) and progesterone in Nigerian women undergoing in vitro fertilization pre and post treatment and their possible effect on pregnancy outcome. Findings from this study will add to the existing level of information/knowledge on pro-inflammatory cytokines and their association with IVF treatment, which will beneficialin improving the success rate in Nigeria. Hence, this study was done to evaluate the levels and relationship between circulating pro-inflammatory cytokines (IFN- $y$, $\mathrm{TN}-\alpha)$ and progesterone in Nigerian Women undergoing in vitro fertilization pre and post treatment and their possible effect of pregnancy outcome.

\section{MATERIALS AND METHODS}

\subsection{Patients}

This observational study randomly selected sixty-two (62) infertile females below 45 year of age who enrolled in the IVF treatment at Lily Hospitals, Warri and Shepherd Specialist Hospital, Warri, Southern Nigeria. Only data of the thirteen (13) infertile females who became pregnant after the IVF treatment where followed up and presented in this study.

\subsection{Pre-Blood Samples Collection}

Five (5) $\mathrm{ml}$ of whole blood were collected into plain tubes on day 3 of the menstrual cycle of all the participants from the ante-cubital vein before IVF procedure using standard laboratory collection technique into an anticoagulant free vacutainers, subsequently centrifuged at 5000 rpm for 5 minutes to obtain serum and stored at $20^{\circ} \mathrm{C}$ until the day of analysis.

\subsection{Post- Blood samples Collection}

Five $(5 \mathrm{ml})$ of whole blood were collected from the thirteen participants at 2 weeks of gestation using standard laboratory collection technique into an anticoagulant free vacutainers, subsequently centrifuged at $5000 \mathrm{rpm}$ for 5 minutes to obtain serum and stored at $-20^{\circ} \mathrm{C}$ until the day of analysis. Within the period of the study, 62 of such women were recruited for the study. However 13 of them became pregnant and were followed up although the number dropped to 10 and 6 by second and third trimesters respectively. Two factors were responsible for the drop, the first being the cost of antenatal care at the IVF centres and the financial capability of the pregnant women. Secondly, stability of the pregnancy encourages such women to continue antenatal care within their locality where they preferred to have their baby.

\subsection{Exclusion Criteria}

Exclusion was based on infertile women who met the criteria of recruitment such as age but had additional health challenges such as hypertension, metabolic syndromes and other chronic infections as retrieved from their case file. Women who are surrogates (carrying pregnancy for other women without using their own oocytes) were also excluded from this study.

\subsection{Stimulation Protocol}

Ovarian stimulation protocol using the long Gonadotropin-Releasing Hormone (GnRH) agonist protocol as described by Tan et al. [19].

\subsection{Oocyte Retrieval/Embryo Transfer}

Oocyte retrieval transfer was done by the reproductive physician, using ultrasound-guided fine-needle aspiration and embryo transfer was done using ultrasound-guided embryo transfer as described by lyoke et al. [20]. 


\subsection{Research Grant}

The study was funded by TETFUND research grant (TETFUND/DESS/NAU/AWKA/RP/Vol. VIII) awarded to Prof. Chinedum Onyenekwe.

\subsection{Determination of Hormone and Cytokine Concentrations}

The levels of progesterone were determined using enzyme-linked immunosorbent assay (ELISA) method as described by Fabien et al. [21] Serum Interferon Gamma were determined using competitive binding immunoassay using ELISA method as described by Thum et al. [22] While serum Tumor Necrosis Factor Alpha were determined by Sandwich-ELISA method as described by Farney et al. [23].

\subsection{Statistical Analysis}

The statistical analysis was done using statistical package for the social sciences (SPSS) version 20.0. One-way analysis of variance with least significant difference post hoc was used to compare mean values of the assayed parameters between the four groups (preprocedure, first, second and third trimesters of gestation).The probability values less than 0.05 were considered significant.

\section{RESULTS}

This prospective observational longitudinal study of 13 randomly selected women within the age range of 30-41 years who underwent IVF treatment (Table 1). The mean serum progesterone levels for pre-procedure, first, second and third trimesters were $2.09 \pm 0.81$, $40.80 \pm 7.40,59.82 \pm 7.95$ and $179.92 \pm 29.07$ respectively. There was significant difference in the mean values of serum progesterone before and after procedure $(p=0.000)$ (Table 2). The mean serum tumor necrotic factor alpha levels for pre-procedure, first, second and third trimesters were $5.57 \pm 2.19,7.73 \pm 1.29,15.59 \pm$ 3.28 and $21.37 \pm 2.47$ respectively. There was significant difference in the mean values of serum tumor necrosis factor alpha before procedure and first trimester of gestation $(p=$
0.000) (Table 2). The mean serum interferon gamma levels for pre-procedure, first, second and third trimesters were $27.59 \pm 57.91,56.57 \pm$ $6.13,28.11 \pm 7.14$ and $27.53 \pm 6.40$ respectively. There was significant difference between mean values of interferon gamma pre-procedure and first trimester $(p=0.031)$ (Table 2).

\section{DISCUSSION}

Several non-Nigerian studies tried to relate hormone and cytokine concentrations in follicular fluid to oocyte maturity and fertilization results (see Introduction). This first Nigerian study randomly selected13 infertile women within the age range of 30-41 years who underwent IVF treatment and became pregnant. The study sets out to observe the levels and relationship between circulating pro-inflammatory cytokines (IFN- $\gamma$, TNF- $\alpha$ ) and progesterone in Nigerian women undergoing in vitro fertilization before and after treatment and their possible effect of pregnancy outcome. The elevated levels of IFN$\mathrm{Y}$, TNF- $\alpha$ and progesterone concentrations in pregnant women with successful oocyte fertilization and post fertilization development, as demonstrated in this study, suggests that these, and probably other, locally acting factors play an important role in determining oocyte implantation and developmental competence.

Concentrations of $\mathrm{IL}-1$ and TNF- $\alpha$ in human follicular fluid, in relation to IVF results, were analyzed previously by two independent studies. [3-4] in which a positive correlation between IL-1 and TNF- $\alpha$ concentrations, but no correlation between the concentration of either cytokine and oocyte fertilization or embryo quality, was found. Our data support only the former observation because the elevated TNF- $\alpha$ and IFN-Y concentrations were associated with elevated progesterone in the patients. The fact that the pregnant women with elevated progesterone also had the high concentrations of circulating proinflammatory cytokines (IFN- $y$, TNF- $\alpha$ ) supports the hypothesis that both cytokines are involved in the regulation of processes influencing successful pregnancy outcome. It also strongly suggests that both cytokines may

Table 1. Demographic data of women undergoing in vitro fertilization treatment

\begin{tabular}{ll}
\hline Total number of clients followed up & $\mathbf{1 3}$ \\
\hline Age Range & $30-41$ years \\
Patients (mean \pm SD age (year) & $37 \pm 5.0$ \\
Clients with Previous IVF & 04 \\
Clients for First Attempt & 09 \\
\hline
\end{tabular}


Table 2. Comparison of (means \pm SD) of serum progesterone $(\mathrm{ng} / \mathrm{ml})$ pre-procedure, first trimester, second trimester and third trimester of women undergoing in vitro fertilization pre and post treatment

\begin{tabular}{|c|c|c|c|c|}
\hline Groups & $\mathbf{N}$ & PROG & TNF- $\alpha$ & IFN- Y \\
\hline Group A (Pre-Procedure) & 13 & $2.09 \pm 0.81$ & $5.57 \pm 2.19$ & $27.59 \pm 57.91$ \\
\hline Group B (First Trimester) & 13 & $40.80 \pm 7.40$ & $7.73 \pm 1.29$ & $56.57 \pm 6.13$ \\
\hline Group C (Second Trimester) & 10 & $59.82 \pm 7.95$ & $15.59 \pm 3.28$ & $28.11 \pm 7.14$ \\
\hline Group D (Third Trimester) & 06 & $179.92 \pm 29.07$ & $21.37 \pm 2.47$ & $27.53 \pm 6.40$ \\
\hline$F$ value & & 307.690 & 84.98 & 2.282 \\
\hline$p$ value & & $0.000^{*}$ & $0.000^{*}$ & 0.095 \\
\hline$A$ vs $B$ & & $0.000^{*}$ & $0.023^{*}$ & $0.031^{*}$ \\
\hline$A$ vs $C$ & & $0.000^{*}$ & $0.000^{*}$ & 0.970 \\
\hline$A$ vs $D$ & & $0.000^{*}$ & $0.000^{*}$ & 0.997 \\
\hline$B$ vs $C$ & & $0.001^{*}$ & $0.000^{*}$ & $0.047^{*}$ \\
\hline$B$ vs D & & $0.000^{*}$ & $0.000^{*}$ & 0.083 \\
\hline C vs D & & $0.000^{*}$ & $0.000^{*}$ & 0.973 \\
\hline
\end{tabular}

act in synergy to ensure the possible release of progesterone which is needed to achieving successful pregnancy outcome. Also, the levels of IFN-y return to baseline during the $2^{\text {nd }}$ and $3^{\text {rd }}$ trimester of pregnancy as demonstrated in this study, suggesting that the stimulatory effect of IFN- $\mathrm{Y}$ are only needed in the $1^{\text {st }}$ trimester of pregnancy. It remains unclear whether elevated IFN- $\gamma$ and TNF- $\alpha$ can directly influence oocyte quality or whether they merely reflect the activity of an independent mechanism that influences successful oocyte implantation, maturation and cytokine production. The demonstration of the type 1 receptor for pro-inflammatory cytokine in mouse oocytes [24], the stimulatory effect of TNF- $\alpha$ on oocyte maturation using animal model [25] and the demonstration that TNF- $\alpha$ can protect isolated mouse oocytes against spontaneous fragmentation [26] suggest a possible role that both pro-inflammatory cytokine plays an important role in successful pregnancy outcome.

The results of several studies indicate that the immune system plays an important role in the etiology of unexplained infertility and in successful implantation. Increased Th1 and Th17 responses have been observed previously in women with reproductive failure, and Th2 responses have been associated with successful pregnancy. It had also been reported that proinflammatory cytokine such as IL-1, IFN- $y$ and TNF- $\alpha$ may be instrumental in operating the periovulatory switch of the follicular steroid production from estradiol to progesterone predominance during pregnancy $[27,28]$ through their inhibitory effect on FSH-induced estradiol production by granulosa cells [29-32]. It had also been reported that TNF- $\alpha$ can stimulate angiogenesis [33], and IL-1, in addition to stimulating TNF- $\alpha$ secretion, is known to enhance directly vascular permeability $[34,35]$.

\section{CONCLUSION}

It is evident from the study that both proinflammatory cytokines (IFN- $\gamma$ and TNF- $\alpha$ ) act in synergy to maintain the level of progesterone which act as an anti-inflammatory agent to regulate the activities of the pro-inflammatory cytokines for successful oocytes implantation and maturation.

\section{CONSENT}

Informed and written consent was obtained from the participants before the commencement study.

\section{ETHICAL APPROVAL}

Ethical approval was sought from the Central Ethics Committee of the Nnamdi Azikiwe University with a reference number: NAU/CEC/STU/EXT/003.

\section{ACKNOWLEDGEMENTS}

We acknowledge tetFUND Nigeria for their sponsorship of this research. We also acknowledge Mr Raphael Olisa, Dr Ufuoma 
Eyeregba and $\mathrm{Dr}$ Imo Iheyichukwu of Lily Hospitals and Miss Ediri of Shepherd Hospital for their technical support.

\section{COMPETING INTERESTS}

Authors have declared that no competing interests exist.

\section{REFERENCES}

1. Nagy ZP, J Liu J, Joris H, Verheyen G, Tournaye G, Camus M, Derde MP, Devroey $P$, Van-Steirteghem AC. Andrology: The result of intracytoplasmic sperm injection is not related to any of the three basic sperm parameters, Human Reproduction. 1995;10(5):1123-1129.

2. Gougeon A. Regulation of ovarian follicular development in primates: Facts and hypotheses. Endocr Rev. 1996;17:121155.

3. Matzuk MM, Lamb DJ. The biology of infertility: Research advances and clinical challenges. Nature Medicine. 2008;14(11): 1197-1213.

4. Barak V, Mordel N, Holzer H. The correlation of interleukin 1 and tumour necrosis factor to oestradiol, progesterone and testosterone levels in periovulatory follicular fluid of in-vitro fertilization patients. Hum Reprod. 1992;7:462-464.

5. Bili H, Tarlatzis BC, Daniilidis M. Cytokines in the human ovary: Presence in follicular fluid and correlation with leukotriene B4. J. Assist Reprod Genet. 1998;15: 93-98.

6. Terranova PR, Hunter VJ, Roby KF, Hunt JS. Tumor necrosis factor-alpha in the female reproductive tract. ProcSocExpBiol Med. 1995;209:325-342.

7. Murphy SP, Tayade C, Ashkar AA, Hatta $\mathrm{K}$, Zhang J, Croy BA. Interferon $\mathrm{Y}$ in successful pregnancies.Biol Reprod. 2009; 80:848-859.

8. Szekeres-Bartho J, Polgar B. PIBF: The Double Edged Sword. Pregnancy and Tumor. Am J Reprod Immunol. 2010;64: 77-86.

9. Sacks GP, Studena K, Sargent K, Redman CW. Normal pregnancy and preeclampsia both produce inflammatory changes in peripheral blood leukocytes akin to those of sepsis. American Journal of Obstetrics and Gynecology. 1998;179(1):80-86.

10. Raghupathy R. Th1-type immunity is incompatible with successful pregnancy. Immunol Today. 1997;18:478481.

11. Jenkins $C$, Wilson $R$, Roberts $J$, Miller $H$, McKillop JH, Walker JJ. Antioxidants: Their role in pregnancy and miscarriage. Antioxid Redox Signal. 2000; 2:623-628.

12. Reid JG, Simpson NA, Walker RG, Economidou O, Shillito J, Gooi HC, Duffy SR, Walker JJ. The carriage of proinflammatory cytokine gene polymorphisms in recurrent pregnancy loss. American Journal of Reproductive Immunology. 2001;45:35-40.

13. Ehiaghe FA, Agbonlahor DE, Ehiaghe IJ, Ositadima MI. Elevation of human chorionic gonadotropin hormone and fibrinogen concentration as an immunoprotective mechanism during pregnancy. Journal of Advances in Biology. 2014;3:253-256.

14. Tavmergen E, Tavmergen EN, Capanoglu $R$. Do analogues of gonadotrophinreleasing hormone influence follicular fluid steroids, oocyte maturity and fertilization rates? Hum Reprod. 1992;7:479-482.

15. Yding-Andersen C, Westergaard LG, Sinosich MJ, Byskov AG. Human preovulatory follicular fluid: Inhibin and free steroids related to optimal follicular maturation in ovarian stimulation regimes and possible function in ovulation. Hum Reprod. 1992;7:765-769.

16. Enien WM, El-Sahwy S, Harris CP. Human chorionic gonadotrophin and steroid concentrations in follicular fluid: the relationship to oocyte maturity and fertilization rates in stimulated and natural in-vitro fertilization cycles. Hum Reprod. 1995;10:2840-2844.

17. Cianci A, Calogero AE, Palumbo MA. Relationship between tumour necrosis factor $\alpha$ and sex steroid concentrations in the follicular fluid of women with immunological infertility. Hum Reprod. 1996;11:265-268.

18. Huyser C, Fourie FLR, Bosmans E, Levay PF. Interleukin1 $\beta$, interleukin-6, and growth hormone levels in human follicular fluid. J. Assist. Reprod Genet. 1994;11:193-202.

19. Branisteanu I, Pijnenborg R, Spiessens C. Detection of immunoreactive interleukin-11 in human follicular fluid: correlations with ovarian steroid, insulin-like growth factor I levels, and follicular maturity. FertilSteril. 1997;67:1054-1058. 
20. Tan SL, Kingsland C, Campbell S, Mills C, Bradfield J, Alexander N, Yovich J, Jacobs HS. The long protocol of administration of gonadotropin-releasing hormone agonist is superior to the short protocol for ovarian stimulation for in vitro fertilization. Fertile Steril. 1992;57(4):810-814.

21. lyoke CA, Ugwu GO, Ezugwu FO, Ajah LO, Mba SG. The role of ultrasonography in in-vitro fertilization and embryo transfer. Niger J Med. 2013;22(3):162-170.

22. Fabien $R$, Réjean $C L$, Sandra $B$, Christopher $P$. Accuracy of a rapid enzyme-linked immunosorbent assay to measure progesterone in mares. Can Vet J. 2007;48:823-882.

23. Thum MY, Hossam I, Abdalla S, Shree B, Emily L, Harden B, Ford $N$, Sumar $H$, Shehata $A B$. The relationship of systemic TNF-alpha and IFN-gamma with IVF treatment outcome and peripheral blood NK cells. Am J Reprod Immunol. 2007;57: 210-217.

24. Farney JK, Mamedova LK, Godsey BH, Bradford BJ. Technical note: validation of an ELISA for measurement of tumor necrosis factor alpha in bovine plasma. J Dairy Science. 2011;94(7):3504-3509.

25. Simon C, Frances A, Piquette G, Polan ML. Immunohistochemical localization of the interleukin-1 system in the mouse ovary during follicular growth, ovulation and luteinization. Biol Reprod. 1994;50: 449-457.

26. Takehara $\mathrm{Y}$, Dharmarajan AM, Kaufman $G$, Wallach EE. Effect of interleukin-1 $\beta$ on ovulation in the in vitro perfused rabbit ovary. Endocrinology. 1994;134:23012308.

27. Sato E, Nakayama T, Kamio K. Immunohistochemical localization and possible roles of tumor necrosis factor- $\alpha$ in mouse cumulusoocyte complexes. Develop. Growth Differ. 1995;37:413-421.

28. Adashi EY. The potential relevance of cytokines to ovarian physiology: The emerging role of resident ovarian cells of the white blood cell series. Endocr Rev. 1990;11:454-464.

29. Machelon V, Emilie D. Production of ovarian cytokines and their role in ovulation in the mammalian ovary. Eur Cytokine Netw. 1997;8:137-143.

30. Fukuoka M, Yasuda K, Fujiwara $\mathrm{H}$. Interactions between interferon $\mathrm{Y}$, tumour necrosis factor $\alpha$, and interleukin-1 in modulating progesterone and oestradiol production by human luteinized granulosa cells in culture. Hum Reprod. 1992;7: 1361-1364.

31. Watanabe $H$, Nagai $K$, Yamaguchi $M$. Concentration of interleukin-1 $\beta$ correlates with prostaglandin E2 and F2 $\alpha$ in human preovulatory follicular fluid. Hum Reprod. 1994;9:9-12.

32. Best CL, Hill JA. Interleukin-1 $\alpha$ and $-\beta$ modulation of luteinized human granulosa cell oestrogen and progesterone biosynthesis. Hum Reprod. 1995;10: 3206-3210.

33. Rice VM, Williams VR, Limback SD, Terranova PF. Tumour necrosis factor- $\alpha$ inhibits follicle stimulating hormoneinduced granulosa cell oestradiol secretion in the human: Dependence on size of follicle. Hum Reprod. 1996;11:1256-1261.

34. Leibovich SJ, Ploverini PJ, Shepard HM. Macrophageinduced angiogenesis is mediated by tumor necrosis factor-alpha. Nature. 1987;329:630-632.

35. Dinarello CA. Biology of interleukin-1. FASEB J. 1988;2:108-115.

(C) 2020 Osakue et al.; This is an Open Access article distributed under the terms of the Creative Commons Attribution License (http://creativecommons.org/licenses/by/4.0), which permits unrestricted use, distribution, and reproduction in any medium, provided the original work is properly cited.

Peer-review history:

The peer review history for this paper can be accessed here: http://www.sdiarticle4.com/review-history/56246 